\title{
Aa. Vv., Campistron et consorts: tragédie et opéra en France (1680-1733)
}

\section{Daniela Dalla Valle}

\section{(2) OpenEdition}

1 Journals

\section{Edizione digitale}

URL: http://journals.openedition.org/studifrancesi/34653

DOI: 10.4000/studifrancesi.34653

ISSN: 2421-5856

\section{Editore}

Rosenberg \& Sellier

\section{Edizione cartacea}

Data di pubblicazione: 1 novembre 2005

Paginazione: 414

ISSN: 0039-2944

\section{Notizia bibliografica digitale}

Daniela Dalla Valle, «Aa. VV., Campistron et consorts: tragédie et opéra en France (1680-1733)», Studi Francesi [Online], 146 (XLIX | II) | 2005, online dal 30 novembre 2015, consultato il 20 avril 2021. URL: http://journals.openedition.org/studifrancesi/34653; DOI: https://doi.org/10.4000/studifrancesi. 34653

Questo documento è stato generato automaticamente il 20 avril 2021.

\section{(c) $(1) \ominus$}

Studi Francesi è distribuita con Licenza Creative Commons Attribuzione - Non commerciale - Non opere derivate 4.0 Internazionale. 


\title{
Aa. Vv., Campistron et consorts: tragédie et opéra en France (1680-1733)
}

\author{
Daniela Dalla Valle
}

\section{NOTIZIA}

Campistron et consorts: tragédie et opéra en France (1680-1733), «Littératures classiques», 52, automne 2004, pp. 424.

1 Il volume - che supera notevolmente il margine cronologico del XVII secolo, anche se in quel periodo pone le sue radici - propone le comunicazioni del Colloquio Campistron et consorts, che si svolse a Tolosa nel 2002. Jean-Philippe Grosperrin presenta l'insieme del colloquio e del volume (pp. 5-17), quindi gli articoli sono raggruppati in tre diverse sezioni. Ricordiamo qui i titoli e gli autori degli articoli stessi. In primo luogo - sotto il titolo Après Corneille et Racine, après Quinault et Lully: états et empires de la tragédie (1680-1733) - si analizza il genere tragico, con le sue diverse versioni, nel periodo studiato. Gli articoli sono: Sur le Racine mort, qu'est-ce au juste qui pullule? di J.-N. Pascal, Tragédies bibliques et chrétiennes di A. Blanc, Le dernier Boyer, d'Agamemnon à Judith di Ch. Mazouer, Théorie et pratique des citations de Corneille et de Racine chez Marie-Anne Barbier di C.Montoya, Les «beautés de Racine» selon le P. Brumoy di E. Flamarion, Le plaisir tragique selon l'abbé Dubos di C. Cammagre, Spectacle tragique et frontières génériques [...] dans les tragédies de Crébillon di M.Soulatges, Marivaux et la tragédie di J.Dagen, PierreCharles Roy, un Ancien parmi les Modernes di R. Fajon e Galanterie, tragique et théâtralité chez Houdar de la Motte di I. Galleron-Marasescu.

2 Segue la sezione intitolata Tragédies et opéras: le cas de Campistron, che comprende dieci articoli: Campistron, ou la défaite du mythe sur la scène tragique di Chr. Delmas, D'une prétendue mollesse: galanterie et modernité de Campistron di C. Barbafieri, Campistron ou les possibles d'une inflexion élégiaque de la tragédie di E. Van der Schueren, Ethique et politique des larmes dans Virginie de Campistron di S. Marchand, Racine, Campistron et les Livres des Rois di J .Dubu, Campistron et les transformations de l'espace scénique: les scènes d'amants 
surpris di R. Bret-Vittoz, L'univers nouveau de la tragédie en musique: d'Armide et Renaud à Achille et Polyxène di B. Norman, Opéra et fable tragique: l'adaptation du sujet d'Hercule sur l'Oeta dans Alcide de Campistron di B.Louvat-Molozay, Fureur féminines en musique dans Achille et Polyxène et Alcide di M.Adamo, Arminius en Italie: de la tragédie française au dramma per musica di F. Lévy.

3 Infine alcuni articoli concernono La tragédie déclamée et/ou la tragédie en musique: deux aspects en interaction: La tragédie, et après? Autopsie d'un recentrage générique à la fin du Grand Siècle di G. Spielman, Tragédies en musique et tragédies déclamées: Antoine Danchet, un dramaturge habile di L.Naudeix, Tragédie et opéra, entre théorie et pratique: Longepierre et $L a$ Motte di S. Hache, De quelques usages du choeur chez Quinault et de leurs échos chez Racine et Voltaire di M. Couvreur e La musique des larmes, d'Alceste à Zaïre di C. Guyon-Lecoq.

4 Segue una ricca Bibliografia su Tragédie et opéra en France (1680-1733), elaborata da J.-Ph. Grosperrin.

5 Ci scusiamo di aver offerto soltanto l'indice dei volume, ma soffermarci in questa sede sull'uno o l'altro articolo non ci è parso giusto, piuttosto che segnalare - anche soltanto con il rinvio al titolo - l'insieme del panorama analizzato. L'interesse del volume infatti, deriva soprattutto da questa rivisitazione di un settore teatrale non molto sfruttato, ma recentemente riproposto dalla critica agli studiosi del periodo. 